\title{
Um Relato de Experiência da Aplicação de Videoaulas de Programação de Jogos Digitais para Alunos da Educação Básica
}

\author{
Thiago Reis da Silva ${ }^{1,2}$, Eduardo H. S. Aranha ${ }^{2}$, Felipe G. Santos ${ }^{3}$, Kleber F. \\ Tavares $^{2}$ \\ ${ }^{1}$ Instituto Federal de Educação, Ciência e Tecnologia do Maranhão - IFMA \\ ${ }^{2}$ Programa de Pós-Graduação em Sistemas Computacionais - PPgSC \\ Universidade Federal do Rio Grande do Norte - UFRN \\ Laboratório Gamedu.net \\ ${ }^{3}$ Instituto Federal de Educação, Ciência e Tecnologia do Piauí - IFPI \\ thiago.reis@ifma.edu.br, eduardoaranhaddimap.ufrn.br, \\ felipe.goncalves@ifpi.edu.br, kleber76@gmail.com
}

\begin{abstract}
This article presents an experience report with respect to the application of digital games programming video classes with 60 students of secondary and high education. The focus of the article is to evaluate the choices made in the production process of the videos, detailing their intrinsic aspects. The results show the acceptance of this resource to support game programming learning for young students and the need for more studies to promote the development of games for introducing programming skills in initial years of education through video classes.
\end{abstract}

Resumo. Neste artigo apresentamos um relato de experiência da aplicação de videoaulas de programação de jogos digitais com 60 alunos da Educação Básica. O foco do artigo está em avaliar as escolhas realizadas no processo de produção das aulas, detalhando aspectos intrínsecos dos vídeos. Os resultados evidenciam a aceitação deste recurso no apoio à aprendizagem de programação de jogos para este público e a necessidade de mais estudos para promover o desenvolvimento de jogos, para introduzir conhecimentos de programação na educação básica através de videoaulas.

\section{Introdução}

Apesar de a Computação estar presente na maioria dos setores da sociedade, existe uma carência de conhecimento e interesse da população nesta área. Uma das razões é a ausência do ensino de Computação no Ensino Básico e o baixo despertar vocacional dos jovens para as áreas tecnológicas. Observa-se que o ensino focado somente no manuseio da informática não é mais suficiente. Na Educação Básica, é importante ensinar a proficiência digital, incluindo o ensino de algoritmos e de programação, além do pensamento computacional. Percebendo a importância em desenvolver desde as séries iniciais o ensino de programação, os Estados Unidos e países da Europa têm implantado um currículo mínimo de Computação em suas escolas [CSTA 2011].

$\mathrm{Na}$ atualidade, é requerido aos estudantes desenvolver habilidades que lhes permitam conviver em um mundo cada vez mais tecnológico. Nesse contexto, faz-se necessário uma compreensão sobre os conceitos fundamentais da Ciência da Computação, em especial, o ensino de programação. Uma das formas de se promover 
essa compreensão é através de videoaulas disponibilizadas na Internet. Entretanto, a viabilidade do ensino de programação para o público jovem através de videoaulas ainda carece de mais evidências de suporte, dada a complexidade do tema trabalhado.

Neste contexto, a presente pesquisa tem por objetivo apresentar um relato de experiência da aplicação de videoaulas de programação de jogos digitais on-line. Neste estudo, 60 alunos foram observados em um ambiente virtual on-line de aprendizagem de programação de jogos. Os resultados revelam que as videoaulas de desenvolvimento de jogos permitem a aprendizagem de conceitos de programação de uma forma divertida e promovem o interesse e a motivação dos alunos para a área de Ciência da Computação.

Para apresentar o trabalho realizado, este artigo segue organizado em sete seções, começando com esta introdução. Em seguida, a Seção 2 apresenta a fundamentação teórica, enquanto a Seção 3 o contexto do estudo. Já a Seção 4 aborda as videoaulas produzidas e na Seção 5 são apresentados os resultados da avaliação das mesmas. Por fim, na Seção 6 são apresentadas as considerações finais.

\section{Fundamentação Teórica}

Essa seção irá apresentar uma breve fundamentação sobre o ensino de programação na Educação Básica e sobre aprendizagem on-line.

\subsection{Ensino de Programação na Educação Básica}

Há vários fatores que apontam a relevância da inserção do ensino de programação nas escolas [CSTA 2011]. Em Scaico et. al., (2013), dois fatores são realçados. O primeiro é que o ensino de programação permite o desenvolvimento de capacidades que contribuem para melhorar o pensamento computacional dos alunos, e o segundo é que essa proximidade pode ajudar a definir a visão e as atitudes dos estudantes em relação à utilização de tecnologias que eles costumam manipular.

Nesta perspectiva, alguns países já implementaram um currículo de programação em suas escolas [CSTA 2011]. A Estónia implementou um programa para o ensino de programação para estudantes a partir de sete anos [Olson 2012]. Os Estados Unidos têm se preocupado em formar essas competências desde cedo, a partir das séries iniciais. Isto porque segundo Scaico et. al., (2013), os governos desses países entendem que isso gerará impactos nas suas economias e na capacidade que seus cidadãos terão para se adaptar às mudanças. No entanto, na maioria dos países a aprendizagem de conceitos de programação na escola não é viável devido à falta de recursos (professores preparados, laboratórios de informática, e outros), abrindo uma oportunidade para os ambientes de aprendizagem de programação on-line.

\subsection{Aprendizagem On-line}

Novas práticas no ensino incluem o uso de videoaulas. O objetivo do uso de videoaulas é enriquecer o processo de ensino e aprendizagem. Videoaulas para conteúdos relacionados com a aprendizagem de programação são facilmente encontrados na Internet. Muitos professores criam materiais para apoiar a aprendizagem dos alunos e divulgam na Internet, por exemplo, através do YouTube. Essas videoaulas possuem características marcantes pelo fato de realizarem explicações sobre algum algoritmo escrito em alguma linguagem de programação [Raabe, Bernardes e Augusto Junior 
2014]. Estudos também destacam a eficiência das videoaulas no processo de aprendizagem de programação [Urquiza-Fuentes, Hernan-Losada e Martin 2014], no entanto, esses estudos são focados para o contexto do ensino superior.

As principais diferenças das videoaulas com outros métodos de ensino são os seguintes [Hanrong 2013]: instrutivo, incentivar os alunos a pensar de forma independente; ênfase prática, enfatizando a capacidade de aplicação; e a ênfase no trabalho em equipe, desenvolvendo o senso de colaboração dos alunos. No entanto, é importante ter videoaulas apropriadas para estudantes do Ensino Básico, por estes estarem em formação inicial e possuírem linguagem e comportamentos próprios.

\section{Contexto do Estudo}

Este estudo foi realizado no contexto de um desafio de capacitação e competição de programação de jogos on-line, cujos objetivos são: promover o ensino de programação na Educação Básica; desenvolver habilidades do século XXI dos alunos através de atividades de desenvolvimento de jogos; e envolver os alunos e professores em atividades que estimulem o conhecimento sobre o pensamento computacional e utilização de jogos na educação.

Este desafio de programação de jogos foi realizado através de um Ambiente Virtual de Aprendizagem (AVA), com videoaulas que ensinam programação de jogos usando a ferramenta Construct2. Esta ferramenta possibilita criar jogos 2D para dispositivos móveis, web e desktop através do encaixe de blocos de comando, tendo o usuário que se preocupar apenas com a lógica de funcionamento do jogo.

O desafio foi dividido em três fases: Divulgação, Capacitação e Competição. A fase de Divulgação foi realizada através das mídias sociais (Facebook, Google+, entre outras) e visitas a algumas escolas na cidade do Natal, no Rio Grande do Norte. A fase de Capacitação visou preparar os alunos no desenvolvimento de jogos com a ferramenta Construct2. A fase de Competição visou avaliar, selecionar e premiar os melhores jogos do desafio. Nesta etapa os participantes criaram equipes de dois a cinco integrantes e submeteram um jogo. Cada equipe tinha um professor como orientador, pois todos os jogos desenvolvidos nesta etapa tinham que ser jogos com fins educacionais.

Os alunos tiveram acesso às videoaulas durante os meses de outubro e novembro de 2015. As videoaulas foram disponibilizadas no AVA, onde os alunos podiam acessar as aulas e tirar suas dúvidas através dos fóruns e chats do ambiente. Em cada aula era apresentado um jogo diferente trabalhando conceitos diversos, como variáveis e apresentando funcionalidades do Construct2. No total foram disponibilizados três conjuntos de videoaulas, cada conjunto ensinando a desenvolver um jogo diferente. Os temas dos jogos utilizados na etapa de capacitação foram: Arkanoid, Jogo da Nave e Destroyer.

Cada conjunto de videoaula era composto pelos vídeos necessários para se desenvolver um jogo. Esse jogo possuía uma videoaula de apresentação e outros vídeos denominados de recursos que explicavam elementos da ferramenta de programação e de conceitos básicos de programação necessários para se desenvolver o jogo. 
V Congresso Brasileiro de Informática na Educação (CBIE 2016)

Anais do XXII Workshop de Informática na Escola (WIE 2016)

As videoaulas foram desenvolvidas em um formato no qual os alunos precisariam pensar mais em como desenvolver o jogo, trabalhando o raciocínio lógico, sistematização e outras habilidades para organizar o desenvolvimento do jogo.

Os participantes do estudo foram 60 estudantes da Educação Básica, sendo 51 meninos e 9 meninas. O estudante mais jovem tinha 12 anos, mas a maioria deles tinham 18 anos. A identificação do perfil dos participantes foi realizada através de um questionário. A Tabela 1 apresenta a quantidade de participantes por nível de escolaridade.

Tabela 1: Quantidade de alunos por nível de escolaridade.

\begin{tabular}{|c|c|}
\hline Nível de Ensino & Quantidade \\
\hline Ensino Fundamental & 6 \\
\hline Ensino Médio & 30 \\
\hline Ensino Médio Integrado ao Técnico & 24 \\
\hline Total & $\mathbf{6 0}$ \\
\hline
\end{tabular}

\section{Videoaulas Produzidas}

Uma videoaula é um recurso multimídia que tem por finalidade auxiliar alguém a aprender algo, independentemente da forma ou área de conhecimento [Barrére, Scortegagna e Lélis 2011]. As videoaulas desenvolvidas para este estudo segue um estilo quebra-cabeças, proposta por Silva et. al., (2015), no qual se apresenta um vídeo de abertura mostrando o jogo a ser desenvolvido e desafiando o aluno a criá-lo, e um conjunto de outros vídeos que dão a base para se desenvolver o jogo, apresentando os passos para se implementar funcionalidades do jogo como, por exemplo, dar movimento aos seus personagens. Todos os vídeos são reutilizáveis, por exemplo, se o jogo 1 e o jogo 2 possuem elementos que atiram, ambas as aulas desses jogos farão referência ao mesmo vídeo do recurso do comportamento Bullet da ferramenta Construct2.

As videoaulas de abertura possuem aproximadamente 2 minutos e as de recurso variam entre 2 a 6 minutos. Para Dotta et. al., (2013) o tempo de uma videoaula não deve extrapolar 25 minutos. Silva e Aranha (2015) em seu estudo detectou que quanto mais longas são as videoaulas, maior a chance dos alunos desistirem de assistir, e Silva et. al., (2015), confirmou em seu estudo que videoaulas de até 20 minutos são boas para ensinar.

Como exemplo das videoaulas desenvolvidas, será apresentada na Tabela 2 a estrutura da videoaula do jogo Arkanoid. Para esse jogo foi desenvolvido um conjunto composto por 14 vídeos.

Tabela 2: Estrutura das videoaulas do jogo Arkanoid.

\begin{tabular}{|c|l|c|l|}
\hline Vídeo & \multicolumn{1}{|c|}{ Título do Vídeo } & Tempo & \multicolumn{1}{c|}{ Descrição das funcionalidades } \\
\hline Vídeo 1 & $\begin{array}{l}\text { Demonstração do Jogo } \\
\text { Arkanoid }\end{array}$ & $0: 28$ & Demonstração de como funciona o jogo. \\
\hline Vídeo 2 & $\begin{array}{l}\text { Montar cenário - Tiled } \\
\text { Background }\end{array}$ & $4: 47$ & $\begin{array}{l}\text { O Tiled Background é usado para colocar o } \\
\text { plano de fundo do jogo. }\end{array}$ \\
\hline Vídeo 3 & Montar cenário - Sprite & $3: 00$ & $\begin{array}{l}\text { O Sprite é utilizado para colocar objetos no } \\
\text { jogo. }\end{array}$ \\
\hline Vídeo 4 & $\begin{array}{l}\text { Montar cenário - Grade } \\
\text { e Copiar Objetos }\end{array}$ & $1: 33$ & $\begin{array}{l}\text { Grade é utilizada para mostrar uma grade na } \\
\text { tela e Copiar é fazer uma cópia dos objetos. }\end{array}$ \\
\hline
\end{tabular}


V Congresso Brasileiro de Informática na Educação (CBIE 2016)

Anais do XXII Workshop de Informática na Escola (WIE 2016)

\begin{tabular}{|c|c|c|c|}
\hline Vídeo 5 & Montar cenário - Text & $3: 11$ & $\begin{array}{l}\text { O Text é empregado para colocar informações } \\
\text { textuais. }\end{array}$ \\
\hline Vídeo 6 & $\begin{array}{l}\text { Movimento da Barra - } \\
\text { 8direction }\end{array}$ & $3: 28$ & $\begin{array}{l}\text { 8direction é usado para colocar movimento } \\
\text { para } 8 \text { direcões no objeto. }\end{array}$ \\
\hline Vídeo 7 & $\begin{array}{l}\text { Movimento da Barra - } \\
\text { Bound to Layout }\end{array}$ & $1: 15$ & O Bound to Layout deixar o objeto Sólido. \\
\hline Vídeo 8 & $\begin{array}{l}\text { Movimento da Barra - } \\
\text { Solid }\end{array}$ & $1: 18$ & Solid impedir objeto de sair do cenário. \\
\hline Vídeo 9 & $\begin{array}{l}\text { Movimento da Bola - } \\
\text { Bullet }\end{array}$ & $2: 00$ & Bullet fazer o objeto se mover como uma bola. \\
\hline Vídeo 10 & $\begin{array}{l}\text { Movimento da Bola - } \\
\text { Keyboard }\end{array}$ & $5: 49$ & Keyboard aceitar entradas do teclado. \\
\hline Vídeo 11 & Pontuação - Variáveis & $1: 32$ & $\begin{array}{l}\text { As variáveis servem para armazenar valores } \\
\text { numéricos ou textuais. }\end{array}$ \\
\hline Vídeo 12 & $\begin{array}{l}\text { Pontuação }- \text { Colisão } \\
\text { entre Objetos }\end{array}$ & $2: 03$ & Usado para criar colisões entre objetos. \\
\hline Vídeo 13 & Pontuação - Pontuação & $2: 57$ & Usado para criar a pontuação do jogo. \\
\hline Vídeo 14 & $\begin{array}{l}\text { Derrota no Jogo - } \\
\text { Restart Layout }\end{array}$ & $5: 55$ & $\begin{array}{l}\text { Restart Layout reiniciar cenários e eventos do } \\
\text { jogo. }\end{array}$ \\
\hline
\end{tabular}

\section{Avaliação das Videoaulas}

O objetivo principal da avaliação foi mensurar a qualidade das videoaulas produzidas e a aceitação deste tipo de material didático por parte deste público alvo. Assim sendo, para tal objetivo avaliou-se os seguintes aspectos: (C1) tempo da videoaula; (C2) qualidade do áudio da videoaula; (C3) forma de explicação do conteúdo; (C4) como os estudantes se sentiram ao assistir as videoaulas. Por exemplo, se se recomendariam para outros colegas. Os alunos ainda puderam opinar sobre os pontos positivos e negativos das vídeoaulas e a complexidade dos jogos apresentados nas videoaulas.

Para coletar as opiniões dos estudantes foi elaborado um questionário on-line composto por uma parte para identificação do perfil dos participantes e outra de opiniões sobre as videoaulas. Para a elaboração do questionário houve um cuidado a fim de não enviesar as respostas. Por exemplo, utilizou-se a escala de Likert, oferecendo aos estudantes a mesma quantidade de respostas negativas e positivas. Por exemplo, para a questão "Q1: O que você achou do tempo da videoaula?" Existem cinco possíveis respostas: Excelente (E), Bom (B), Regular (R), Ruim (RU) e Péssimo (P). A Tabela 3 apresenta as respostas dos critérios $(\mathrm{C} 1, \mathrm{C} 2, \mathrm{C} 3$ e $\mathrm{C} 4)$ analisados pelos alunos.

Tabela 3: Critérios avaliados.

\begin{tabular}{|l|c|c|c|c|c|}
\hline \multicolumn{1}{|c|}{ Critérios } & E & B & R & RU & P \\
\hline C1: o que você acha do tempo da videoaula? & 26 & 25 & 5 & 2 & 2 \\
\hline C2: O que você achou da qualidade do áudio da videoaula? & 17 & 31 & 10 & 2 & 0 \\
\hline $\begin{array}{l}\text { C3: O que você achou das explicações apresentadas na } \\
\text { videoaula? }\end{array}$ & 18 & 37 & 4 & 1 & 0 \\
\hline C4: Recomendaria para seus colegas & 30 & 28 & 2 & 0 & 0 \\
\hline
\end{tabular}

Em relação ao critério $\mathrm{C} 1$ a maioria dos estudantes acharam o tempo da videoaula adequado. Sendo que $86 \%$ dos alunos responderam positivamente ao tempo das videoaulas ( $44 \%$ excelente e $42 \%$ bom). Isso demonstra que as videoaulas foram capazes de atingir o objetivo, que era ensinar programação de jogos em um tempo que 
não fosse exaustivo aos alunos e de uma forma simples e lúdica. Destaca-se também que $8 \%$ responderam regular, $3 \%$ ruim e $3 \%$ péssimo. Os $14 \%$ de insatisfação foram atribuídos ao pouco tempo das videoaulas, pois os vídeos tinham em torno de 6 minutos, e para esses alunos as videoaulas deveriam ter um tempo maior.

No critério C2, 28\% responderam excelente e 52\% bom. Estes dados mostram que $80 \%$ que acharam a qualidade do áudio ideal, que foi feita utilizando-se um microfone semiprofissional em uma sala fechada (mas não isolada acusticamente). Além disso, $17 \%$ responderam regular e 3\% ruim. Nenhum estudante respondeu péssimo. Este resultado aponta para a relevância da qualidade do vídeo utilizado.

Em relação sobre ao critério (C3), os estudantes responderam que eles se sentiam mais confiantes à medida que as explicações iam se aprofundando em mais recursos e mais conceitos relacionados à programação de jogos eram apresentados. Os resultados mostram que a maioria ficou satisfeita com as explicações: $30 \%$ reportaram que acharam excelente, $61 \%$ bom, $7 \%$ regular e $2 \%$ ruim. Para o critério C4, 97\% dos alunos recomendaria para outras pessoas.

Ficou evidente que os alunos se sentiram motivados e estimulados a buscarem o conhecimento dentro desta atividade através das videoaulas. É possível observar que os exemplos adotados, o tempo e a qualidade dos vídeos foram bem avaliados pelos estudantes, além de representar uma evidência de que os alunos gostariam de ter uma disciplina de programação de jogos digitais nas escolas. Essa evidência ficou notória com o seguinte questionamento: Com que frequência você gostaria de ter videoaulas de programação de jogos digitais nas escolas?

Como observado na Figura 1, os alunos deste nível de ensino têm interesse em aprender programação nas escolas e de preferência semanalmente. Esse fator mostra a necessidade de mais pesquisa que insira este conteúdo para os alunos matriculados na Educação Básica. Estes dados justificam a necessidade desse estudo, para trabalhar entre outros aspectos o pensamento computacional nas escolas e atrair novos talentos para a Computação.

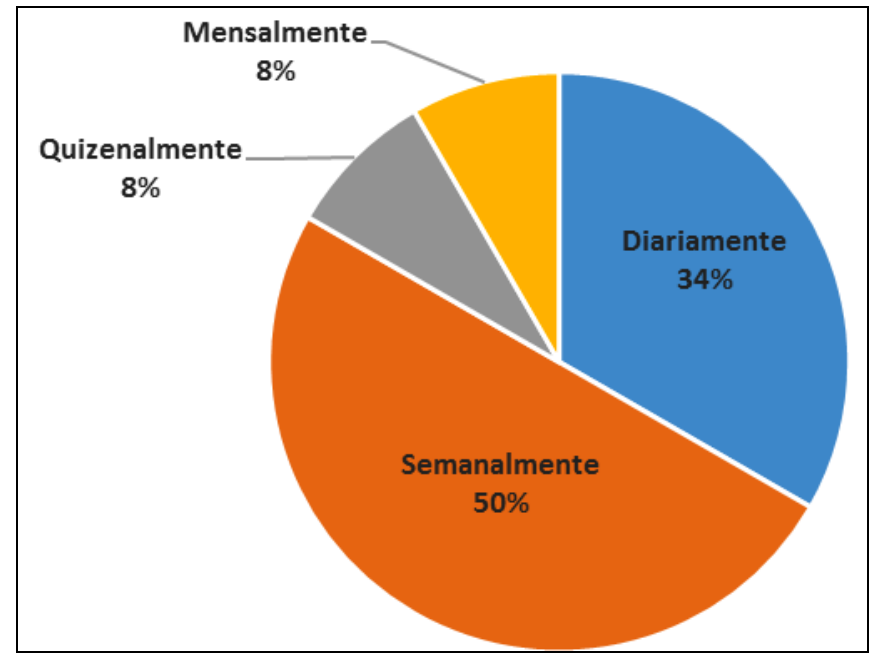

Figura 1. Frequência de aulas de programação de jogos digitais nas escolas. 
V Congresso Brasileiro de Informática na Educação (CBIE 2016)

Anais do XXII Workshop de Informática na Escola (WIE 2016)

Neste estudo, foram direcionadas duas questões discursivas para que os participantes expressassem sua opinião sobre os pontos positivos e negativos das videoaulas. Os principais pontos positivos que os alunos destacaram foram:

- "A divisão da aula em etapas ajuda principalmente na hora em que recorremos aos vídeos para identificar algum erro, pois basta pesquisar pela etapa em que se está com dificuldade";

- "Muito bem explicativas, dinâmicas e interativas";

- "No meu ponto de vista, ela abre portas para a melhoria no desenvolvimento de jogos, pois serviu como um norte, e contribuiu para o interesse em querer aprender mais sobre o assunto, e mostrou também que não é tão complicado assim desenvolver um jogo";

- "Estão bem programadas e estruturadas".

Os principais pontos falhos apontados pelos alunos foram:

- "Poderiam ser citados outras aplicações práticas das ferramentas ensinadas nos vídeos, tais como jogos RPG";

- "O fato de dividir as aulas em etapas pode causar certo desconforto em pessoas que tenham preguiça de assistir ao ver a quantidade de videoaula. Se de alguma forma puder colocar uma porcentagem em um videoaula, indicando o progresso do aluno ao invés de escolher a aula livremente...".

Outra análise feita a partir dos dados dos alunos que responderam ao questionário referiu-se ao grau de dificuldade que eles tiverem para desenvolver os jogos. Para analisar o nível de dificuldade dos alunos diante da criação do jogo, os mesmos poderiam escolher entre as opções: (i) fácil, (ii) médio e (iii) difícil.

A análise dos resultados apresenta que a maioria dos alunos reportou que a atividade de criação dos jogos não era fácil e nem difícil, ou seja, de dificuldade moderada. $46 \%$ dos alunos acharam que era fácil e 55\% apontam essa tarefa apresentou uma dificuldade moderada. Uma parcela muito pequena dos alunos $(2 \%)$ considerou a elaboração de jogos difícil. Desta forma, pode-se observar que a maioria dos alunos não encontrou grandes dificuldades ou impedimentos em desenvolver seus jogos.

Para finalizar o questionário, foi elaborada a seguinte questão. “A experiência com o desenvolvimento do jogo com o uso de videoaulas te motiva a aprender conceitos de programação".

$\mathrm{Na}$ análise dos resultados foi possível verificar 95\% dos alunos considera que essa experiência motivou os mesmos a aprender outros conceitos de programação. E $100 \%$ dos alunos reportaram que participaria novamente de outros estudos dessa natureza. Isso vai de encontro a uma opinião de um aluno: "Foi uma das melhores atividades que fiz nesse ano e acho que devia ser mais divulgada nos próximos anos, irei procurar saber mais sobre programação e jogos". Outro ponto determinante, é que o dinamismo viabilizado pelos jogos permite o trabalho de diferentes aspectos lúdicos no processo de aprendizagem. Ao mesmo tempo em que o aluno está aprendendo, ele está se divertindo, ou seja, a própria natureza do jogo estimula um maior interesse do aluno com o aprendizado. 
Sendo assim, dadas às dificuldades do estudo, os resultados indicam que os estudantes receberam com satisfação o ensino de programação de jogos digitais on-line através das videoaulas. No entanto, aprendemos que esse público alvo precisa de uma quantidade significativa de videoaulas e de um mecanismo para guiar esse processo de aprendizagem para que as aulas se tornem ainda mais interativa e que consequentemente os alunos realizem todas as atividades solicitadas. Aprendemos também que os alunos querem uma disciplina dessas nos currículos das escolas, como apresentado na Figura 1.

Visando apresentar evidências sobre o resultado de aprendizagem dos alunos em termos de programação de jogos digitais, alguns dos jogos desenvolvidos pelos próprios alunos na fase de competição (após assistirem os conjuntos de videoaulas disponibilizados no AVA na fase de capacitação), são apresentados na Tabela 4.

Tabela 4: Jogos desenvolvidos.

\begin{tabular}{|c|c|l|}
\hline $\begin{array}{c}\text { Nome do } \\
\text { Jogo }\end{array}$ & $\begin{array}{c}\text { Temática do } \\
\text { Jogo }\end{array}$ & \multicolumn{1}{|c|}{ Descrição } \\
\hline $\begin{array}{c}\text { Desafio } \\
\text { RN do }\end{array}$ & $\begin{array}{c}\text { Geografia e } \\
\text { matemática }\end{array}$ & $\begin{array}{l}\text { Testar o conhecimento do jogador no aspecto de } \\
\text { geolocalização dos municípios no mapa do estado do Rio } \\
\text { Grande do Norte. }\end{array}$ \\
\hline $\begin{array}{c}\text { Coleta } \\
\text { Seletiva }\end{array}$ & Biologia & $\begin{array}{l}\text { O jogo tem como objetivo instruir as pessoas, principalmente } \\
\text { estudantes do ensino básico (faixa de idade: 4-12 anos), a } \\
\text { identificar e separar corretamente os tipos de lixo recicláveis } \\
\text { (vidros, metais, plásticos e papéis). }\end{array}$ \\
\hline $\begin{array}{c}\text { Super } \\
\text { Dente }\end{array}$ & Saúde Bucal & $\begin{array}{l}\text { Jogo de caráter lúdico e educativo tendo como objetivo } \\
\text { ensinar sobre a proteção bucal, enquanto diverte. }\end{array}$ \\
\hline Enegma & Foco no ENEM. & $\begin{array}{l}\text { Jogo de plataforma que visa fazer com que o jogador exercite } \\
\text { sua aptidão para o ENEM ao mesmo tempo em que se insere } \\
\text { numa aventura do jogo. }\end{array}$ \\
\hline Bio Keeper & Biologia & $\begin{array}{l}\text { Jogo fundamentado na ideia de ecossistema baseado nos } \\
\text { Objetivos do Milênio propostos pela ONU. Neste jogo o } \\
\text { jogador tem que controlar uma nave que viaja pelo planeta } \\
\text { para resolver seus problemas e manter o equilíbrio da vida. }\end{array}$ \\
\hline $\begin{array}{c}\text { Prova dos } \\
\text { Sonhos }\end{array}$ & $\begin{array}{c}\text { Português, } \\
\text { Matemática, } \\
\text { Ciências, } \\
\text { História e } \\
\text { Geografia }\end{array}$ & $\begin{array}{l}\text { O jogo é dividido em cinco fases, sendo as quatro primeiras } \\
\text { compostas, cada uma, por disciplinas do Ensino Básico } \\
\text { (Português, Matemática, Ciências, História e Geografia). Em } \\
\text { cada fase, são apresentadas cinco dicas e perguntas de } \\
\text { assuntos relacionados a disciplina daquela fase, fazendo com } \\
\text { que o jogador tenha domínio sobre todas as questões } \\
\text { educacionais levantas. }\end{array}$ \\
\hline
\end{tabular}

Para se ter uma análise dos jogos desenvolvidos, exemplificamos a ideia do jogo Mapa do RN (Figura 2). O objetivo do jogo é identificar a localização de cidades no mapa do RN, encontrando o maior número possível de municípios dentre os 167 existentes no estado, até que a barra de progresso chega a $0 \mathrm{~km}$. Inicialmente é oferecido a cada jogador $1000 \mathrm{~km}$ de distância para que ele possa encontrar o lugar exato da cidade dentro mapa. Desta forma, quanto menor for a distância (erro) entre a posição real do município em relação ao lugar identificado pelo o jogador, menor é o desconto na barra de progresso. Para o desenvolvimento do jogo os alunos usaram recursos do Construct2 como o Point-and-Click, ou seja, aponte e clique, aprendido na fase de capacitação. No caso exemplificado na Figura 2, a cidade que o jogo solicitou para que o aluno identificasse no mapa foi Galinhos. Como podemos observar na Figura 2, 
V Congresso Brasileiro de Informática na Educação (CBIE 2016)

Anais do XXII Workshop de Informática na Escola (WIE 2016)

quando o aluno escolhe a cidade no mapa aparece a diferença entre a cidade apontada e o local correto. Além disso, é oferecida com fins educativos ao aluno uma breve descrição da cidade e uma imagem da mesma.

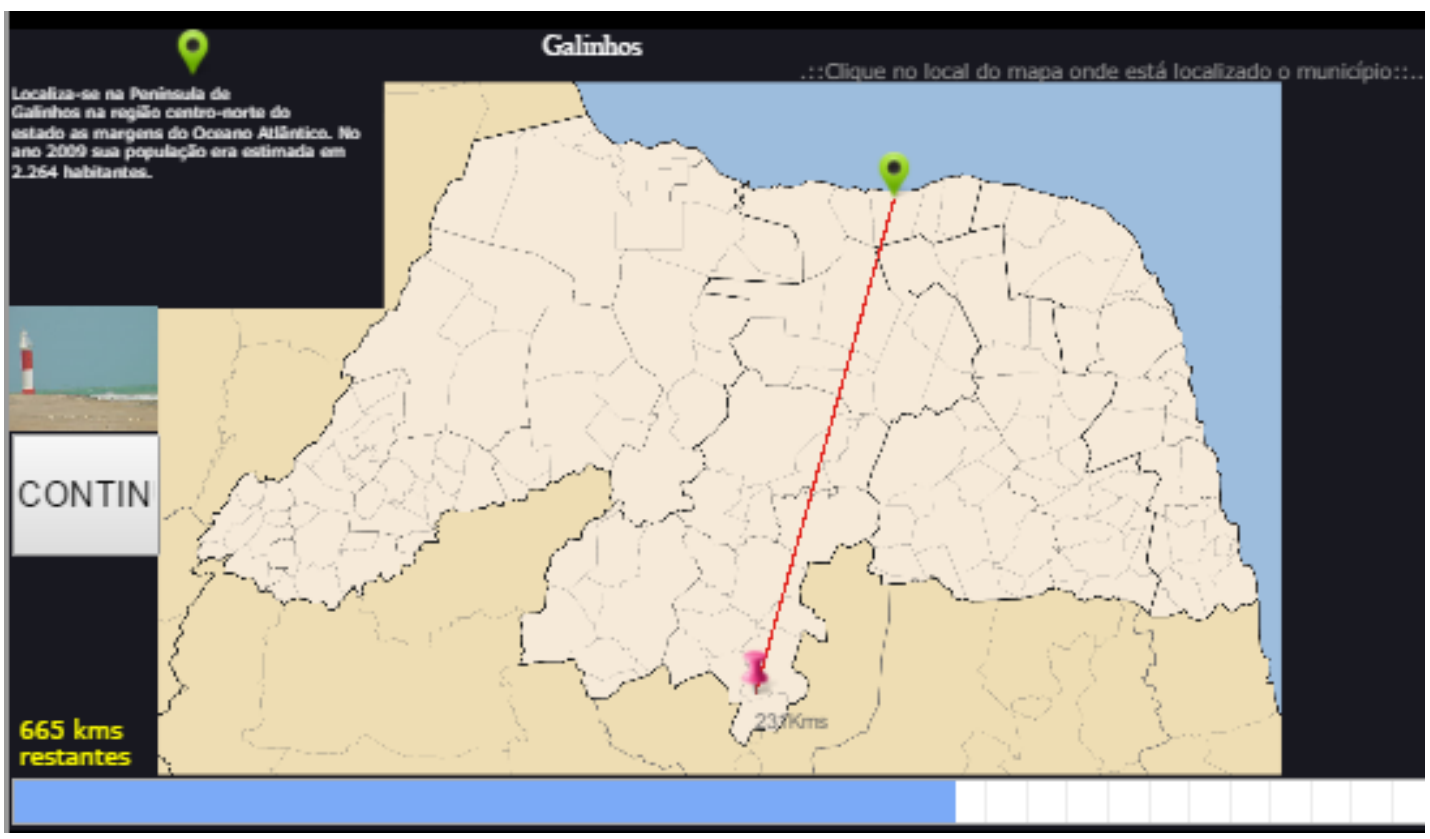

Figura 2: Jogo Mapa do RN.

Portanto, acreditamos que é de suma importância inserir esse conhecimento na Educação Básica, permitindo a integração de disciplinas, que através do desenvolvimento de um jogo, animação ou simulação, os alunos possam abordar conceitos de outras disciplinas como matemática, física e português, com o intuito de unificar os conhecimentos em ambientes lúdicos.

\section{Considerações finais e trabalhos futuros}

Este artigo teve por objetivo relatar os resultados da aplicação de videoaulas de programação de jogos com alunos da Educação Básica - Ensino Fundamental e Médio e de avaliar as preferências dos estudantes no uso de videoaulas para o ensino de programação de jogos digitais. A análise foi realizada a partir de um questionário aplicado aos participantes, concentrando-se em questões que discutiam aspectos de qualidade das videoaulas e de seus formatos.

$\mathrm{Na}$ análise dos dados foi constatado que 100\% dos alunos consideram importante o recurso de videoaulas. Isso é visível nos comentários dos alunos durante o estudo, pois foi perceptível que, com essa abordagem, facilitou-se a compreensão no assunto. De fato, foi possível os alunos seguirem as explicações do assunto e realizarem a resolução do problema proposto (criação de um jogo).

Por fim, os alunos confirmam que o uso de videoaula facilita a compreensão da programação de jogos, concluindo-se que esse recurso é eficaz quando elaborado de maneira correta. Como perspectiva futura de trabalho pretende-se ampliar a avaliação das videoaulas para uma amostra de estudantes maior, além do desenvolvimento de mais videoaulas. 
V Congresso Brasileiro de Informática na Educação (CBIE 2016)

Anais do XXII Workshop de Informática na Escola (WIE 2016)

\section{Agradecimentos}

Os autores agradecem à CAPES pelo suporte parcial a esta pesquisa, ao Instituto Nacional de Engenharia de Software (INES), ao CNPq, aos integrantes do Laboratório Gamedu.net e, em especial, ao Programa de Pós-Graduação em Sistemas Computacionais - PPgSC/UFRN, por toda infraestrutura oferecida.

\section{Referencias}

Barrére, E.; Scortegagna, L.; Lélis, C. A. S. (2011) "Produção de Videoaulas para o Serviço EDAD da RNP”. In: XXII Simpósio Brasileiro de Informática na Educação SBIE, p.284-293.

CSTA - Computer Science Teacher Association. (2011) "CSTA K-12 Computer Science Standards". CSTA Standards Task Force. ACM Association for Computing Machinery.

Dotta, S. C.; Jorge, Erica F. C.; Pimentel, E. P.; Braga, J. C. (2013) "Análise das Preferências dos Estudantes no uso de Videoaulas: Uma experiência na Educação a Distância”. In: XIX Workshop de Informática na Escola - WIE, p.21-30.

Hanrong, C. (2013) "Video case teaching method in programming courses". In: 8th International Conference on Computer Science and Education - ICCSE, p.10981101 .

Nunes, D. J. (2011). “Ciência da Computação na Educação Básica”. Disponível em: $<$ http://www.adufrgs.org.br/artigos/ciencia-da-computacao-na-educacao-basica/>. Acessado em: maio de 2016.

Olson, P. (2012) "Why estonia has started teaching its first-graders to code". Disponível em: <http:/www.forbes.com/sites/parmyolson/2012/09/06/why-estoniahas-startedteaching-its-first-graders-to-code/>. Acessado: março de 2016.

Raabe, A.; Bernardes, A.; Augusto Junior, R. G. (2014) "Produção e Avaliação de Videoaulas: Um Estudo de Caso no Ensino de Programação". In: XX Workshop de Informática na Escola - WIE, p.448-456.

Scaico, P. D.; Lima, A. A.; Silva, J. B. B.; Azevedo, S.; Paiva, L. F.; Raposo, E. H.; Alencar, Y.; Mendes, J. P.; Scaico, A. (2013) "Ensino de Programação no Ensino Médio: Uma Abordagem Orientada ao Design com a linguagem Scratch". In: Revista Brasileira de Informática na Educação - RBIE, v.21, n.2, p.92-103.

Silva, T. R.; Aranha, E. S. H. (2015) "Online game-based programming learning for high school students - A case study". In: 45th IEEE Frontiers in Education Conference - FIE, p.1-8.

Silva, T. R.; Aranha, E. H. S.; Oliveira, W.; Fernandes, K. T.; Lucena, M. J. N. R. "Investigando dois formatos de videoaulas de programação de jogos digitais para alunos do ensino médio”. In: XXI Workshop de Informática na Escola - WIE, p.187196.

Urquiza-Fuentes, J.; Hernan-Losada, I.; Martin, E. (2014) "Engaging students in creative learning tasks with social networks and videobased learning". In: 44th IEEE Frontiers in Education Conference - FIE, p.1-8. 